\title{
FORMAÇÃO DE ENFERMEIROS E A MUNICIPALIZAÇÃO DA SAÚDE NO BRASIL: A IMPORTÂNCIA DAS POLÍTICAS E DAS PRÁTICAS ${ }^{1}$
}

\author{
EDUCATION OF NURSING PROFESSIONALS AND MUNICIPAL \\ MANAGEMENT OF HEALTH: THE IMPORTANCE OF \\ POLICIES AND PRACTICES \\ ENSEÑANZA DE ENFERMERIA Y MUNICIPALIZACIÓN DE LA SALUD EN \\ BRAZIL: LA IMPORTANCIA DE LAS POLITICAS Y DE LAS PRÁCTICAS
}

\author{
Eliete Maria Silva ${ }^{2}$ \\ Márcia Regina Nozawa ${ }^{3}$ \\ Joyce Lenora Douglas Freitas ${ }^{4}$
}

\begin{abstract}
RESUMO: Objetivando elucidar os pontos centrais a serem considerados no ensino de graduação em saúde e em enfermagem quanto às politicas de saúde contemporâneas, com destaque para o processo de municipalizaçăo, partimos da abordagem histórica das políticas de saúde. A seguir pontuamos características do movimento da Reforma Sanitária e do projeto neoliberal na saúde. para depois apresentar a constituição do Sistema Único de Saúde (SUS). Tomando um de seus principios operacionais fundamentais, que é o da descentralização com comando único em cada nivel de governo, abordamos a municipalização dos serviços e das políticas públicas que condicionam a saúde. As quais dependem de que se aumente a capacidade de decisão local, a autonomia, o controle e a participação social. Considerando experiências concretas, destacando aspectos dos recursos humanos e enfermagem e da organização dos serviços, exemplificando aquelas realizadas em: Ribeirão Preto e Campinas.
\end{abstract}

PALAVRAS-CHAVE: enfermagem de saúde coletiva, ensino de enfermagem, politicas de saúde, municipalização em saúde

\section{INTRODUÇÄO}

Além da educação continuada dos profissionais que já estão inseridos nos serviços públicos de saúde e concretamente atuando na conformação do sistema de saúde, temos que nos preocupar com a formação dos novos agentes que estão por ingressar no mercado de trabalho. Qual é a perspectiva de formação colocada para a enfermagem brasileira quando se encerra o século XX? Privilegiarmos as políticas oficiais de organismos nacionais e internacionais como tem sido a tônica da enfermagem desde seus primórdios? Ou optar por incorporar de forma crítica e radical movimentos democráticos da sociedade e do setor saúde, que alcançaram ser expressos em algumas políticas que ainda almejam ser efetivadas?

Acreditamos que os agentes centrais desta transformação săo os trabalhadores da saúde, dentre estes, a presença da enfermagem é muito significativa. Certamente podemos fazer a diferença, mas precisamos ter projetos concretos nesta direção.

A organização dos serviços de saúde na atualidade passa por várias transformações que

\footnotetext{
'Prémio Isaura Barbosa Lima. $2^{\circ}$ lugar. $51^{\circ}$ CBEn, 1999.

${ }^{2}$ Enfermeira. Professora Doutora do Departamento de Enfermagem da FCM / UNICAMP.

${ }^{3}$ Enfermeira. Professora Doutora do Departamento de Enfermagem da FCM / UNICAMP.

4 Enfermeira do Departamento de Enfermagem da FCM / UNICAMP. Mestre pela FSPIUSP.
} 
carecem ser mais sistematizadas enquanto conhecimentos necessários aos profissionais da saúde. Conhecer mais e de forma didática contribui para ampliar as capacidades de intervenção tanto nas políticas sanitárias quanto no cotidiano dos serviços, onde se efetivam e conformam o sistema de saúde brasileiro.

Assim, contribuir para elucidar os pontos centrais a serem considerados no ensino de graduação em saúde e em enfermagem quanto às políticas de saúde contemporâneas, com destaque para o processo de municipalização é o objetivo central do presente trabalho.

A proposta de municipalização dos serviços e das ações de saúde foi considerada pela primeira vez na realidade brasileira por ocasião da $3^{\text {a }}$ Conferência Nacional de Saúde (CNS), ocorrida em 1963. Contudo, vários foram os revezes vividos por nossa sociedade naquele período com o subseqüente golpe de Estado que deu inicio à ditadura militar. Com a centralização e o autoritarismo que se implantaram inúmeros projetos que implicavam mudanças nas relações de poder estabelecidas foram sustados, dentre eles a municipalização da saúde.

Esta proposta de descentralizar os serviços de saúde volta a ser veiculada no país no bojo do movimento da Reforma Sanitária. Tal movimento se consolida na década de 1980, de modo que iniciamos por caracterizar em linhas gerais a situação do setor saúde na década chamada, por alguns economistas, como a "década perdida".

A seguir pontuamos características do movimento da Reforma e do projeto neoliberal na saúde, para depois apresentar a constituição mesma do Sistema Único de Saúde (SUS).

Tomando um de seus princípios operacionais fundamentais, que é o da descentralização com comando único em cada nível de governo, abordamos a municipalização. Considerando, à guisa de conclusão, algumas experiências concretas e exitosas.

\section{O SETOR SAÚDE NO BRASIL DOS ANOS 80}

Na década de 1980 ocorrem no país uma profunda crise econômica, caracterizada por políticas econômicas recessivas especialmente nos primeiros anos da década, ao mesmo tempo em que no âmbito político se inicia e aprofunda a redemocratização.

O setor saúde encontrava-se estruturado na perspectiva do Sistema Nacional de Saúde (legislado em 1975, enquanto desdobramento da $5^{\mathrm{a}} \mathrm{CNS}$ ), ou seja, apresentava-se bastante dividido e fragmentado uma vez que:

- ações de prevenção e controle de doenças eram de competência do ministério da saúde (MS), através das secretarias estaduais e dos centros de saúde;

- ações de assistência médica individual eram de competência do ministério da previdência e assistência social (MPAS); e

- ficando ainda as ações de saneamento ou de formação de recursos humanos como competência de outros ministérios, sem a necessária articulação.

O maior montante de recursos financeiros gastos com saúde era da Previdência, que então vivia uma crise profunda caracterizada em três âmbitos:

1. crise ideológica resultante do embate entre o modelo de atenção ao processo saúdedoença vigente no pais e aquele defendido por organismos internacionais, tais como a Organização Pan-americana de Saúde (OPAS), que em parceria com técnicos de vários ministérios construíram o Programa Nacional de Serviços Básicos de Saúde - o PREV-SAÚDE - que no embate com grupos de interesse no setor articulados com a burocracia estatal acabou por ser um programa que nunca saiu das gavetas;

2. crise financeira provocada em parte pela politica recessiva e em parte pelas fraudes, sendo aqui um dos protagonistas centrais a Federação Brasileira de Hospitais; nesse âmbito delineia-se a proposta, que se consolida depois no "carro-chefe" do modelo neoliberal, a alternativa da Associação Brasileira de Medicinas de Grupos (Abramge) de assistência de "custo zero"; 
3. crise político institucional com a criação de uma instância reguladora do sistema o Conselho Consultivo da Administração da Saúde Previdenciária (Conasp), criado em 1981.

Nesta década o desempenho dos indicadores de saúde apontam como problemas especialmente aqueles relacionados à assistência à saúde, como é o caso da mortalidade matema. Contraditoriamente indicadores tais como o da mortalidade infantil sofrem melhoras, que devem se associar à progressiva inserção das mulheres no mercado formal de trabalho, além da maior urbanização da população e discretas, mas sensiveis, melhorias na escolaridade, especialmente das mulheres.

Outro aspecto fundamental a destacar nessa década é a maior organização da sociedade, não só nos partidos politicos, mas também nos movimentos civis, dentre os quais mencionamos os das associações de moradores e das mulheres, que dadas as suas especificidades tomam, desde então, a "questão saúde" como problema e espaço de reivindicação.

\section{A Reforma Sanitária e o projeto neoliberal na Saúde}

O movimento da Reforma Sanitária brasileira começa a ser gestado ainda durante a ditadura militar, nas criticas ao modelo hegemônico da medicina assistencial-privatista, que nos anos 90 , desdobra-se no projeto neoliberal.

A Reforma caracteriza-se por um amplo debate sobre novos modelos organizacionais na saúde e como um movimento de recomposição das forças (politicas, econômicas e sociais) atuantes no setor. Tem se conceituado como um processo modernizador e (re)democratizante de transformações nos âmbitos: político jurídico, político institucional e político operativo.

A Reforma culminou em março de 1986 na $8^{\text {a }}$ CNS com a proposição do Sistema Único de Saúde e com a concepção da saúde como direito de cidadania e dever do Estado. Em grande medida conformando o texto constitucional em seus artigos 196 a 200, que tratam da saúde, no capítulo segundo, da Seguridade Social, a qual foi promulgada em 5 de dezembro de 1988.

Alguns aspectos fundamentais desse processo são:

- a abrangência ou ampliação do conceito de saúde, aprofundando o clássico "saúde como bem estar físico, mental e social" (OMS, 1946) e não somente como ausência de doença, para incluir condiçőes adequadas de moradia, transporte, alimentação, acesso à terra, emprego, renda, liberdade de expressão, dentre outros, de modo que as politicas sociais articulam-se com as politicas econômicas (e vice-versa);

- saúde como direito de cidadania e dever do estado, como já mencionamos antes;

- caracterização dos serviços de saúde como de relevância pública;

- proposição estratégica do Sistema Único de Saúde, com os princípios de universalidade, integralidade, descentralizaçăo e participação popular; e

- integração da Saúde no espaço mais amplo da Seguridade Social.

No âmbito jurídico vale mencionar, além da Constituição Federal a sua regulamentação promulgada em dois momentos distintos do governo Collor, também a legislação nos espaços estaduais e municipais.

A Lei Orgânica da Saúde 8080 (de 19.07.1990) regulamentou o SUS definindo as condições de promoção, proteção e recuperação da saúde. Mas não regulamentou a participação do setor privado, nem enquanto produtor de insumos e nem como responsável pela atenção médica supletiva, como também não dispôs as condições de regulação do subsistema de alta tecnologia. Parte significativa dessas questōes em aberto continua até a atualidade carecendo de maior regulação.

A Lei Orgânica da Saúde 8142 (de 28.12.1990) dispondo sobre a participação comunitária, através dos Conselhos e Conferências, definiu também os repasses de recursos financeiros intergovernamentais de saúde, criando um Fundo Nacional de Saúde e assinalou que as 
condições necessárias para a participação no SUS que os municipios tem que cumprir são: estabelecer a Fundo Municipal de Saúde; constituir e operar os Conselhos e as Conferências de Saúde; estabelecer um Plano Municipal de Saúde; apresentar Relatórios de Gestão; definir contrapartidas de recursos e formular um Plano de Cargos e Salários.

No ano de 1989 foram promulgadas as Constituições Estaduais, em linhas gerais seguindo o texto federal, em São Paulo foi publicada em outubro. No ano seguinte foi a vez dos municípios. A título de exemplos: em Ribeirão Preto a Lei Orgânica data de 06.04.1990, em Campinas foi promulgada em 30.03.1990, revisada em 1992, sendo que em 02.07.1991, com a Lei nº547, foram criados os Conselhos Locais de Saúde.

Conforme vimos elaborando o movimento da Reforma Sanitária era contra-hegemônico, mas então que projeto é esse o hegemônico? Sem entrarmos no mérito das origens do termo neoliberal, optamos por adotá-lo na perspectiva colocada por Mendes (1994) de ser um projeto conservador, na linha de estratégias de ajuste e estabilização que se caracterizam por:

- privatização: no qual a regulação se dá através dos mecanismos de mercado, contando muitas vezes com subsídios estatais diretos e indiretos que denotam a usurpação do Estado ou do bem público por pessoas ou instituições privadas;

- descentralização: com propósito de aumentar a eficiência e a eficácia dos gastos sociais, mas na perspectiva do Estado mínimo neoliberal, o que ocorre sem dúvida é a fragilização do papel regulador do Estado sobre as politicas sociais e uma diminuição de seu papel redistributivo na sociedade; e a

- focalização: numa situação sempre corrente no setor saúde de recursos escassos, os programas sociais dirigem-se aos setores pobres e/ou marginais da sociedade, parecendo mais uma "neofilantropia" do que propriamente uma política social, muitos projetos de atenção primária para populações específicas, tomadas como grupos de risco, fundamentam-se nessa perspectiva.

Este é o quadro denominado por Mendes (1994) de "universalização excludente". Para este autor a Reforma Sanitária que alcançou grande êxito no âmbito jurídico é negada na prática social pelo exercício tácito de um Estado que atua de modo discriminatório e seletivo.

Campos (1990) critica a produção em serviços de saúde. Em relação às conquistas do movimento da Reforma Sanitária argumenta que: "a lógica do modelo neoliberal é largamente hegemônica na prestação de assistência médico-sanitária e que estamos nos recusando a enfrentá-la. Esta lógica de exclusão, do desrespeito ao paciente, da fragmentação das ações de saúde, predomina nos serviços privados, filantrópicos, federais e também nos municipais. A municipalização por si só não vai alterar esta ordem, mesmo sendo ela perversa para a maioria.(...) Se não derrotarmos a hegemonia da medicina privada, que se revela inclusive na privatização da coisa pública, a municipalização bem como o SUDS ou SUS vão se desmoralizar."

O que nos chama a atenção nas produções de Campos (1990), e, também, do grupo da Universidade Estadual de Campinas (Unicamp) é a proposição de que quem gere e de fato torna efetivas as Politicas de Saúde não é somente o Estado, mas necessariamente também os trabalhadores, todos aqueles, envolvidos no Sistema, do mais alto escalão à "porta de entrada", ao fim (ou começo?) da linha.

Bem, passemos então ao SUS.

\section{O SISTEMA ÚNICO DE SAÚDE}

Para não repetir o que já foi assinalado antes pontuamos sinteticamente as diretrizes básicas do Sistema:

- universalidade: diz respeito ao direito universal, sem quaisquer discriminações às ações e serviços e à saúde enquanto um bem, de forma eqüitativa;

- integralidade: diz respeito à assistência integral em todas as ações e a possibilidade 
de acesso aos serviços e ações que forem necessários a cada situação particular;

- descentralização: refere-se à desconcentração de poder e de recursos administrativos e financeiros, sendo fundamental o comando único em cada nivel de governo, o que constitui-se o próprio processo de municipalização; e a

- participação social: relaciona-se à gestão colegiada do sistema entre o governo, os trabalhadores e a sociedade, sendo de fato o mecanismo capaz de radicalizar a democracia e a transparência fundamentais na gestăo coletiva e pública da saúde.

- hierarquização: propōe a atenção básica em unidades ou centros de saúde como porta de entrada para o sistema e serviços de referência (especializada e hospitalar); além dos serviços de urgência e assistência domiciliar, também deve articular-se com os programas de agentes comunitários e de saúde da familia.

\section{A DESCENTRALIZAÇĀO NA SAÚDE E A MUNICIPALIZAÇĀO DOS SERVIÇOS E DA GESTÃO}

Implementar as diretrizes do SUS implica em pensar diferente e estabelecer de maneira distinta a relação Estado - Sociedade civil. Assim, a descentralização pressupõe um estado aberto, democrático e com cidadãos, que além de serem eleitores também exercem outros papéis tais como o de: participante, supervisor e avaliador da prática de desenvolvimento e de governo no âmbito local, de modo articulado com niveis mais globais (Gawryszewski, 1993).

Além da autonomia financeira e administrativa a idéia de autonomia local se enriquece com outros conhecimentos que acrescentam idéias correlatas e importantes tais como a de preservação da integridade do Eu e da capacidade (ou a discussão sobre) a autogestão. De modo que o município além de dispensar serviços à população e como conseqüência da realização integral da democracia também delibera sobre ações globais com autodeterminação, controle de oportunidades e conveniências regionais, sem contudo cair em particularismos e regionalismos.

Portanto, é fundamental para realizar a municipalização dos serviços de saúde e das políticas públicas que condicionam a saúde que se aumente a capacidade de decisão local, a autonomia, bem como o controle e a participação social, representando assim uma efetiva distribuição de poder.

A reciclagem radical da Reforma Sanitária implica em manter os compromissos do movimento com a solidariedade social que esteve presente em décadas anteriores, especialmente nos anos 80 , aliados a uma maior inteligência estratégica e com menores utilitarismos e maniqueismos políticos.

Nos anos 90 duas Normas Operacionais Básicas (NOB) foram editadas no sentido de ordenar o SUS. As NOB 01/93 e NOB 01/96 configuraram-se como importantes instrumentos de viabilização político-administrativa do processo de descentralização e municipalização dos serviços de ações de saúde (Oliveira Júnior, citado por Campos et al., 1998).

A primeira definiu três modalidades de gestão para os estados e municipios (Incipiente, Parcial e Semiplena) e estabeleceu uma sistemática de relação entre as diversas esferas de govemo pela criação das Comissões Intergestoras Bipartite, nas esferas estaduais, e a Comissão Intergestoras Tripartite, na esfera federal, as quais correspondem a órgãos operacionalizadores das politicas definidas pelos conselhos de saúde nas suas respectivas esferas de competência.

A NOB/96 introduziu para duas as modalidades de gestão: a gestão da atenção básica, que pressupõe o repasse direto ao municipio dos recursos correspondentes à atenção básica de acordo com um cálculo per capita, enquanto as ações de média e alta complexidade e as internações continuam a ser pagas por procedimento, e a gestão plena do sistema municipal de saúde na qual o municipio recebe a totalidade de recurso do teto que passa a incluir, além da assistência, ações de vigilância sanitária e controle das doenças transmissiveis. O município, à exemplo da gestão semiplena, também assume o pagamento dos prestadores de serviços 
de saúde.

Várias questões são apontadas na edição desta segunda NOB, em relação à centralização do poder no âmbito federal. A proposição de programas nacionais, como o de Agentes Comunitários e Saúde Familia, dentre outros, para os quais ocorre o repasse de verbas específicas, num certo sentido, contraria a lógica de descentralização efetiva de recursos e do planejamento em função de necessidades locais.

\section{EXPERIÊNCIAS CONCRETAS}

Á guisa de conclusão listamos alguns contrapontos ao projeto neoliberal na saúde que, justamente por buscar outra direção, dão força para as iniciativas de efetiva implementação do SUS em vários municipios, são eles:

- Os serviços de saúde têm uma natureza econômica distinta de outros bens de consumo, de modo que a saúde não é passivel de troca num mercado, a saúde condiciona a utilização derivada de outros bens e serviços, os indivíduos não são (ou são parcialmente!) soberanos em relação ao seu consumo; o saber necessário ao seu consumo é desigualmente distribuído (saber técnico profissional); a sua utilização e acesso dependem de vários fatores externos à relação produtor - consumidor e ainda há o caráter aleatório de aparecimento das doenças.

- Os mecanismos de mercado têm sido perversos no campo sanitário.

- Penalizam-se financeiramente os velhos, os pacientes crônicos, as crianças, as mulheres...

- No modelo neoliberal os serviços são crescentemente ineficazes, ineficientes e desiguais.

Apesar de todas as dificuldades, mudanças concretas são viabilizadas. Vários trabalhadores, estudiosos e pesquisadores têm desenvolvidos investigações e relatos de experiências sobre o processo de municipalização.

Nem sempre as perspectivas são animadoras, mas vale registrar algumas delas como a de Bauru (3), a de Londrina (9), a de Santos (1) e as de Ribeirão Preto (7), um município com cerca de 500 mil habitantes e Campinas (8), com cerca de um milhão.

Em Campinas a primeira enfermeira foi contratada em 1977, já funcionando como área piloto para a regionalização em saúde, com 18 postos comunitários, em junho de 1978 foi firmado Convênio entre as Secretarias de Saúde do Estado e do Municipio. Em 1983 quando o município contava com 31 postos comunitários, nos quais trabalhavam médicos e auxiliares de saúde e contavam com supervisão de 16 enfermeiras e assinou o convênio das Ações Integradas de Saúde (AIS).

Em Ribeirão Preto que assinou o convênio das AIS no mesmo ano, época em que foi contratada a primeira enfermeira, foi montada uma Unidade Piloto de Atençăo Primária à Saúde e além dos médicos e atendentes existentes no quadro da Secretaria Municipal de Saúde foram também contratadas oito auxiliares.

Em 1987 Ribeirão estruturou-se enquanto Sistema Unificado e Descentralizado de Saúde (SUDS), contava com 19 Unidades Básicas de Saúde (UBS), três Pronto Socorros, eram 40 atendentes, 25 auxiliares e sete enfermeiras.

Em Campinas à época do SUDS o municipio contava com 36 unidades básicas de saúde, passando por reformas nas instalações e priorização dos recursos humanos, expressos através da profissionalização dos auxiliares de saúde através da formação em serviço, via Projeto Larga Escala.

Em 1997 Ribeirão Preto contava com cinco Unidades Básicas e Distritais de Saúde (UBDS), 26 UBS, dois núcleos de atenção psicossocial, um ambulatório de especialidades e um ambulatório de saúde mental. Na enfermagem eram 62 atendentes, 484 auxiliares e 154 enfermeiras contratadas pela Secretaria Municipal de Saúde e 18 pela Secretaria Estadual de Saúde, municipalizadas em 1996. 
O serviços públicos municipais de saúde em Campinas constituiam-se em 45 Centros de Saúde, 13 Centros de Referência, três Ambulatórios de Especialidades, três Unidades de Pronto Atendimento e um serviço de atendimento pré-hospitalar. Na enfermagem eram 105 auxiliares de saúde (atendentes), 955 auxiliares de enfermagem e 226 enfermeiras.

Além do crescimento e qualificação expressiva do pessoal de enfermagem também reconhecemos a ampliação e diversificação dos agentes que trabalham abrindo a perspectiva de trabalho multi e interprofissional, com vistas a maior, ou melhor, integralidade. Acresceramse tecnologias tanto assistenciais quanto de organização e gestão.

Em Ribeirão Preto ampliou-se a rede física, especialmente entre 1986 e 89 . Implantaramse prontuários, vacinação, programas de atenção à saúde e sistemas de informação informatizados em todas as unidades sanitárias municipais. Outro movimento fundamental foi a constituição dos Programas de Integração Comunitária (PIC) que atuam numa perspectiva de saúde integral, o que cria situações novas para os trabalhadores nas unidades e também a estruturação ainda incipiente das Comissōes Locais de Saúde.

Em Campinas a rede física instalada também sofreu ampliação durante as três últimas décadas do século XX, particularmente entre os anos de 1977 e 1983. As unidades básicas de saúde utilizam prontuários familiares e/ou individuais, realizam vacinação, atividades de vigilância epidemiológica, programas de atenção à saúde e contam com computadores em todas as unidades. Os recursos humanos são estimulados à educação continuada em serviço e em cursos de especialização e aperfeiçoamento oferecidos com regularidade pela Unicamp. Praticamente todos os Centros de Saúde tem em seu âmbito o funcionamento de Comissões Locais de Saúde, alguns Distritos já tem a prática de reuniões de Conselhos em seu âmbito e a atuação democrática no Conselho Municipal de Saúde tem sido marcante.

Vários programas e serviços tem sido implementados, inclusive destaca-se a visita e assistência domiciliar, que é uma tendência contemporânea de alteração do modelo hospitalocêntrico, havendo diminuição dos períodos de internação e alta de casos complexos que passam a ser atendidos nas unidades básicas ou no próprio domicilio. Contudo, muitas ações ainda são predominantemente fragmentadas e centradas no modelo biomédico. A medicalização da vida ainda é hegemônica (basta recordar o sucesso do Viagra!).

\footnotetext{
ABSTRACT: In order to clarify central aspects to be considered in undergraduate education both in health sciences and in nursing, regarding contemporary health policies, this article presents a historical appurach with emphasis on municipal health management. The authors point out the characteristic of the Sanitary Reform movement and of the neoliberal project in health, followed by a presentation of the National Health System (SUS). Using as starting point the concept of decentralization (only one command at each level of government) - the authors discuss the elaboration and implementation of public social policies and services at the local level. Which depend on an increase of local decisionmaking capacity, autonomy, control and social participation. The experiences of the cities of Campinas and Ribeirāo Preto are described, with emphasis on aspects related to human resources and nursing. and organization of services.
}

KEYWORDS: collective health nursing, nursing education, health policies, and municipal health management.

\footnotetext{
RESUMEN: Con el propósito de dilucidar los puntos centrales en la enseñanza superior de la salud y de enfermeria cuanto a las políticas de salud contemporáneas, dando énfasis al proceso de municipalización, hemos partido de un enfoque histórico de las politicas de la salud. Después de ello, hemos puntualizado las características del movimiento de la Reforma Sanitaria y del proyecto neoliberal en la salud, para después presentar la estructura del Sistema Único de Salud (SUS).
} 
Tomando uno de sus principios operacionales fundamental, el de la descentralización con un comando único en cada nivel de gobierno, hemos tratado de la municipalización de los servicios y de las políticas públicas que condicionan la salud. Dichas políticas dependen de que se aumente la capacidad de decisión local, la autonomía, el control y la participación social. Se consideran las experiencias concretas; se destacan algunos aspectos de los recursos humanos y de enfermeria y el de la organización de los servicios, y se ejemplifican aquellas, que se han realizado ya en Ribeirão Preto y Campinas.

PALABRAS CLAVE: enfermería en salud colectiva, enseñanza de enfermería, politicas de salud, municipalización en salud

\section{BIBLIOGRAFIA}

CAMPOS, Florianita Coelho B.; HENRIQUES, Cláudio M. P. (Orgs.) Contra a maré à beira mar: a experiência do SUS em Santos. 2.ed. São Paulo: Hucitec, 1997.

CAMPOS, Gastão W.S. Um balanço do processo de municipalização. Saúde em debate, n.28, p.247, 1990.

CAPISTRANO, David; PIMENTA, Aparecida L. Saúde para todos. São Paulo: Hucitec, 1988.

GAWRYSZEWSKI, Virgínia. Reorganização dos Serviços de Saúde Cad.Saúde Públ., v.9, n.2, p.210$15,1993$.

MENDES, Eugênio Vilaça. Distrito Sanitário. São Paulo/Rio de Janeiro: Hucitec/ABRASCO, 1994.

OLIVEIRA JÚNIOR, Mozart. O financiamento da área social e do Sistema Único de Saúde no Brasil. In: CAMPOS, Francisco Eduardo; OLIVEIRA JÚNIOR, Mozart; TONON, Lidia Maria. Cadernos de saúde, Belo Horizonte, Coopmed, p.45-78, 1998. v. 1: Planejamento e gestão em saúde.

PEREIRA, Maria José; FORTUNA, Cinira; SILVA, Eliete Maria; PINTO, Ione C, MISHIMA, Silvana M. As enfermeiras na Secretaria Municipal de Saúde de Ribeirão Preto, 1997. (mimeogr.). ITrabalho apresentado no $5^{\circ}$ Congresso Brasileiro de Saúde Coletiva/.

SILVA, Eliete Maria; NOZAWA, Márcia Regina; CARMONA, Silvia A.P.M.L.D.; SILVA, José Carlos. Práticas das enfermeiras e políticas de saúde pública em Campinas, Brasil, 1999. (mimeogr.). /Trabalho apresentado no $10^{\circ}$ Seminário Nacional de Pesquisa em Enfermagem/.

SILVA, Silvio F. A construção do SUS a partir do municipio. São Paulo: Hucitec, 1996

Recebido em outubro de 1999

Aprovado em maio de 2000 